\title{
Identification of short and long-lived atmospheric trace gases from IASI space observations
}

\author{
Hélène De Longueville ${ }^{1}$, Lieven Clarisse ${ }^{1}$, Simon Whitburn ${ }^{1}$, Bruno Franco ${ }^{1}$, \\ Sophie Bauduin ${ }^{1}$, Cathy Clerbaux ${ }^{1,2}$, Claude Camy-Peyret ${ }^{3}$, and \\ Pierre-François Coheur ${ }^{1}$
${ }^{1}$ Université libre de Bruxelles (ULB), Spectroscopy, Quantum Chemistry and Atmospheric Remote Sensing (SQUARES), Brussels, Belgium
${ }^{2}$ LATMOS/IPSL, Sorbonne Université, UVSQ, CNRS, Paris, France ${ }^{3}$ Institut Pierre Simon Laplace (IPSL), Sorbonne Université, UPMC/UVSQ, Paris, France

\section{Key Points:}

- The whitening transformation allows analyzing anomalies in hyperspectral infrared spectra

- In a biomass burning plume we identify nine compounds including a first observation of glycolaldehyde

- On spectra observed a decade apart we identify atmospheric changes in eight longlived halocarbons

Corresponding author: Hélène De Longueville, Helene.De.Longueville@ulb.ac.be

This article has been accepted for publication and undergone full peer review but has not been through the copyediting, typesetting, pagination and proofreading process, which may lead to differences between this version and the Version of Record. Please cite this article as doi: 10.1029/2020GL091742.

This article is protected by copyright. All rights reserved. 


\begin{abstract}
In recent years, major progress has been made in measuring weakly absorbing atmospheric trace gases from high spectral resolution space observations. In this paper, we apply the so-called whitening transformation on spectra of the Infrared Atmospheric Sounding Interferometer (IASI), and show that it allows removing most of the climatological background from spectra, leaving a residual that contains those spectral signatures that depart from normality. These can subsequently be attributed to changes in the abundance of trace species. This is illustrated for two diverging cases: (1) a biomass burning plume from the 2019/2020 Australian bushfires, leading to the unambiguous identification of nine reactive trace gases, including a first observation of glycolaldehyde; (2) spectra observed a decade apart, from which changes in eight long-lived halogenated substances are identified; three of them never observed before by a nadir sounder.
\end{abstract}

\title{
Plain Language Summary
}

In recent years, several techniques have been developed for the detection of gases present in very small quantities in the atmosphere, which has significantly improved our knowledge on atmospheric composition and chemistry. In this paper, we describe a powerful complementary technique that transforms atmospheric spectra to highlight and attribute the spectral signatures of different species. We apply it on spectra measured by the spaceborne IASI (Infrared Atmospheric Sounding Interferometer) for two different cases: (1) a plume from the 2019/2020 Australian bushfires leading to the clear identification of nine rare gases including a first observation from space of glycolaldehyde; (2) spectra observed a decade apart, of which eight long-lived halogenated substances were identified; three of them never observed before by a nadir sounder. The detection of these reactive and long-lived trace gases is very promising for the monitoring of their temporal evolution and the attribution of their sources.

\section{Introduction}

The outgoing longwave radiation spectrum of the Earth-atmosphere system features strong absorption bands of $\mathrm{CO}_{2}, \mathrm{H}_{2} \mathrm{O}, \mathrm{CH}_{4}, \mathrm{~N}_{2} \mathrm{O}, \mathrm{O}_{3}$ and $\mathrm{CO}$. Routine measurements of several of these strong absorbers are now available from nadir observing polar orbiting infrared sounders, which have led over the years to major advances in our understanding of their distribution (Crevoisier et al., 2014). Unexpectedly, hyperspectral nadir sounders have also proven most useful for the measurements of other, much weaker, absorbers. Harries et al. (2001) for instance demonstrated that infrared sounders can be used to monitor longterm changes of the ozone depleting halocarbons CFC-11 and CFC-12 (see also Coheur et al. (2003)). Beer et al. (2008) and Coheur et al. (2009) showed the first observations of $\mathrm{NH}_{3}, \mathrm{C}_{2} \mathrm{H}_{4}, \mathrm{HCOOH}, \mathrm{CH}_{3} \mathrm{OH}$ and PAN in fire plumes and above highly polluted urban areas. Progress in retrieval techniques (see Franco et al. (2018) and references therein) has now allowed measuring these and other compounds also outside of highly concentrated plumes, in turn leading to major discoveries on their emission sources, e.g. Stavrakou et al. (2011) and Van Damme et al. (2018). Noticeable progress has been made using the Infrared Atmospheric Sounding Interferometer (IASI) on-board the Metop-A/B/C platforms (Clerbaux et al., 2009). The IASI instrument measures a very large continuous part of the thermal infrared $\left(645-2760 \mathrm{~cm}^{-1}\right)$ and, thanks to its high radiometric performances, high spectral resolution $\left(0.5 \mathrm{~cm}^{-1}\right.$, apodized) and bi-daily global coverage, has played a major role in the monitoring of weakly absorbing trace gases (e.g. Clarisse et al. (2011), Hilton et al. (2012) and Franco et al. (2019)). As a summary of past achievements, the list of 29 species that have been observed with IASI, either globally or in concentrated plumes is given in Table 1.

In recent years, remote sensing of weakly absorbing trace gases has benefited greatly from the discovery of improved algorithms for detecting very small features in spectra. In 
particular, the method introduced by Walker et al. (2011) increased drastically the detection sensitivity over traditionally approaches and formed the basis of several quantitative retrieval techniques (Franco et al., 2018; Taylor et al., 2018; Clarisse et al., 2019). In this paper, we introduce a complementary technique based on 'whitening' spectra, which is suitable for analyzing spectra with unknown signatures. In the next section, we review briefly the detection method of Walker et al. (2011) and show how it naturally leads to the concept of whitening spectra. In section 3, we apply it on spectra from the 2019/2020 Australian fires and show that it enables, much easier than with alternative methods, to highlight and identify the different trace gas signatures, leading to the unambiguous identification of nine reactive trace gases. An entirely different application of whitening occurs when spectra are compared to those of a different period. As we show in section 4, whitening allows in this instance, highlighting small changes in a series of long-lived halogenated substances, most of which have until now never been identified in IASI spectra.

Table 1. Chemical species observed by IASI. The species reported in this paper which are observed for the first time with a nadir sounder are indicated in italics.

\begin{tabular}{ll}
\hline Greenhouse gases and ozone-related & $\mathrm{H}_{2} \mathrm{O}, \mathrm{CO}_{2}, \mathrm{CH}_{4}, \mathrm{~N}_{2} \mathrm{O}, \mathrm{O}_{3}, \mathrm{HNO}_{3}, \mathrm{CFC}-11$, \\
& $\mathrm{CFC}-12, \mathrm{HCFC}-22, \mathrm{CCl}_{4}, \mathrm{CF}_{4}, \mathrm{HCFC}-142 b$, \\
& $\mathrm{HFC}-134 a, \mathrm{SF}_{6}$
\end{tabular}

\section{Whitening transformation}

The detection method presented in Walker et al. (2011) is based on a formula that quantifies in a single number the integrated spectral contributions of a target species, in a given spectral range. It relies on the mean $\bar{y}$ and the associated covariance matrix $S$ of a set of spectra that are representative for IASI observations in the absence of enhancements of the target species. The pair $\{\bar{y}, S\}$ describes the distribution of spectra and how they are expected to vary (driven mostly by differences in temperature, surface emissivity, water vapor and interferences with other absorbers). The single number is sometimes referred to as a hyperspectral range index (HRI) (Van Damme et al., 2014) and is defined as

$$
\mathrm{HRI}=\frac{K^{T} S^{-1}(y-\bar{y})}{\sqrt{K^{T} S^{-1} K}},
$$

with $K$ the Jacobian of the target species calculated from radiative transfer simulations (Van Damme et al., 2014). This formula was originally derived from the least squares estimate, and in that context the covariance matrix can be interpreted as a generalized noise covariance matrix, where all background variability is treated as noise. Note that, by construction, the HRI is normalized to provide a mean of zero and a standard deviation of one on the set of background spectra. Its value can therefore be interpreted in terms of standard deviations from the mean. Higher values (typically above $4 \sigma$ in absolute value) usually indicate the presence of an anomalous abundance of the target species (or at least an anomaly in the spectrum that sufficiently resembles its Jacobian). The expression can be interpreted geometrically as the weighted projection of the Jacobian onto the zero-centered observed spectrum.

It turns out that Equation (1) has been known since the 1970s (Reed et al., 1974) under the name 'matched filter' and is used very frequently in the domain of hyperspectral imagery 
(Manolakis et al., 2016). In this field, the covariance matrix is appropriately referred to as the background clutter matrix, the HRI as the signal-to-clutter or signal-to-noise ratio, and its expression is sometimes written as (Manolakis et al. (2016), p520)

$$
\mathrm{HRI}=\frac{\tilde{K}^{T} \tilde{y}}{\|\tilde{K}\|},
$$

with

$$
\begin{gathered}
\tilde{K}=S^{-\frac{1}{2}} K \\
\tilde{y}=S^{-\frac{1}{2}}(y-\bar{y})
\end{gathered}
$$

The operation $y \rightarrow \tilde{y}$, transforms the spectra into a set of spectra with a zero mean and an identity covariance matrix. As this transforms the generalized noise into white noise, the operation is referred to as whitening or pre-whitening (Scharf, 1991; Rodgers, 2000; Manolakis et al., 2016; Kessy et al., 2018). Whitening transforms the spectral channels to uncorrelated random variables with unit variance and zero mean. In this form, the HRI is simply the projection of the whitened spectrum $\tilde{y}$ onto the normalized whitened Jacobian $\tilde{K}$.

Instead of the HRI, one can also analyze the entire unprojected whitened spectra. Whitening removes most of the background signal. Therefore, on background spectra, each channel of a whitened spectrum has an expected mean value of zero and a standard deviation of 1 (this is a property inherited from the HRI). Conversely, a whitened spectral channel with an absolute value above 4 indicates a significant departure from Gaussian normality. Large negative values indicate an anomalous large absorption, while large positive values indicate either an emission signal or a decrease of a given trace gas with respect to background conditions (defined by the set of spectra used to generate $\tilde{y}$ and $S$ ). So rather than associating with each spectra a single number like the HRI, whitening a spectrum produces another spectrum in which all spectral aberrations are exposed. The strength of the whitening technique is that it allows highlighting anomalies without knowing the spectral signature (Jacobian) in advance. Once a candidate species is suspected, it can be unambiguously assigned by comparing the shape of the whitened Jacobian with the spectral signatures in the whitened spectrum. Unambiguous identification is another clear advantage over the HRI, which can be prone to false detections caused by a partial match of a spectral signature with the Jacobian of the target species. Note that by weighting with the inverse of the covariance matrix, the spectral components that normally exhibit the largest variability (e.g. the baseline, due to variation in the surface temperature and clouds, or the absorption features due to $\mathrm{O}_{3}, \mathrm{H}_{2} \mathrm{O}$ or $\mathrm{CO}_{2}$ ) will carry the least weight in the whitened spectrum.

When we talk about departure from normality, this is with respect to a set of spectra taken from a reference time period and/or geographic area of our choice. This freedom gives rise to at least two important applications: (1) when the covariance is representative for the entire set of IASI spectra, whitening can be used to study special events such as volcanic eruptions or large fires; (2) when the covariance matrix is representative for a specific time period and used on spectra from another time period, whitening, as we will show, can reveal small changes in the concentrations of long-lived compounds. A case study of each application is presented next.

As a side comment, the HRI formula can also be derived from standard linear discriminant analysis, and through the use of the covariance matrix, is also closely linked to principal component analysis (PCA). We refer to Clarisse et al. (2013) for a detailed discussion of this. Whitening can be seen as an alternative to PCA-based analysis of anomalies in spectra (Grainger et al., 2013).

Whitening can be seen as an alternative to analyzes based on principal components (PC) (Hurley et al., 2009; Grainger et al., 2013). In such approaches, the signatures of interest are contained in the orthogonal part to the PC. A key difference between the two 


\section{Short-lived gas detection in Australian bushfires}
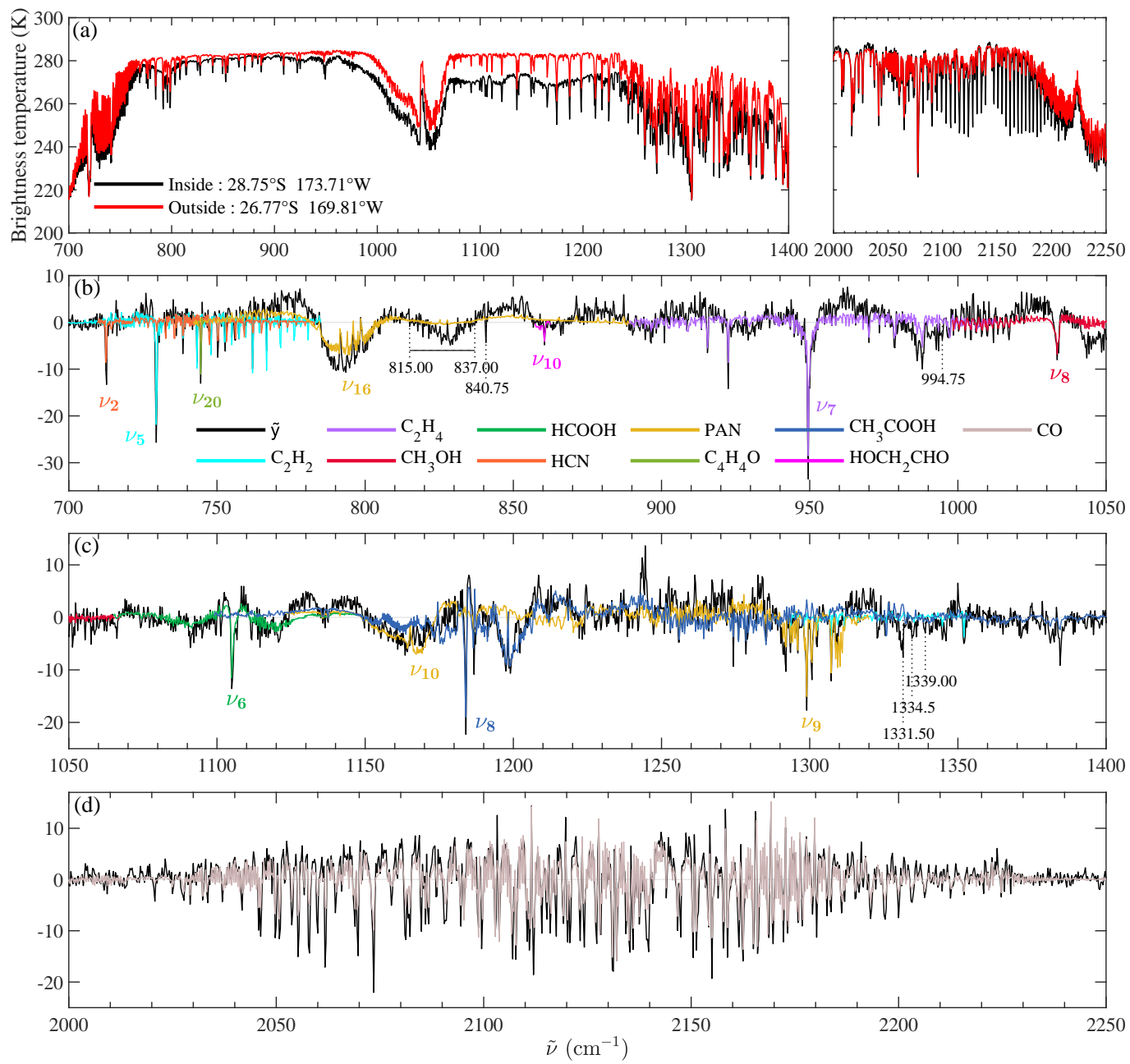

Figure 1. Spectrum from the Australian bushfires of 5 January 2020 revealing nine trace gas species and carbon monoxide. Panel a shows the spectrum as measured by IASI before the whitening transformation (in black), together with a spectrum measured just outside the plume (in red). The whitened spectrum is shown in panels b to $\mathrm{d}$ for selected spectral ranges.

This first case study concerns the massive bushfires which took place in Australia around the turn of year 2019-2020 (Nolan et al., 2020; Boer et al., 2020). IASI spectra of similarly large fires in Australia in 2009 were analyzed in Clarisse et al. (2011) with a physical retrieval approach, and revealed very strong spectral signatures of some well-known fire tracers. Here we will focus on a particular spectrum that was observed over the South 
Pacific Ocean $\left(28.75^{\circ} \mathrm{S}, 173.71^{\circ} \mathrm{W}\right)$ on January 5,2020 . This spectrum was selected on the basis of HRI-maps of $\mathrm{C}_{2} \mathrm{H}_{4}$ (see Figure A1 of Annex A). These indicate that the observation was made in the central part of a large fire plume originating from South-East Australia two or three days earlier. Calipso measurements (Winker et al., 2009) reveal that the plume was located between 4 and $6 \mathrm{~km}$ above sea level.

The chosen (untransformed) spectrum is shown in Figure 1a together with a spectrum measured outside the fire plume (their location is indicated in Figure A1 of Annex A). Immediately obvious is the strong absorption band of CO in the $2100-2200 \mathrm{~cm}^{-1}$ region, and the large absorption in the atmospheric window between 1080 and $1230 \mathrm{~cm}^{-1}$ due to smoke aerosols and other broadband absorbers. Figure $1 \mathrm{~b}-\mathrm{d}$ shows the whitened spectrum calculated with $\{\bar{y}, S\}$ built using a subset of around $10^{7}$ IASI spectra measured throughout 2013 and across the globe, from (Franco et al., 2018). From this spectrum, we identified nine species between 700 and $1400 \mathrm{~cm}^{-1}$, namely acetylene $\left(\mathrm{C}_{2} \mathrm{H}_{2}\right)$, ethylene $\left(\mathrm{C}_{2} \mathrm{H}_{4}\right)$, methanol $\left(\mathrm{CH}_{3} \mathrm{OH}\right)$, formic acid $(\mathrm{HCOOH})$, hydrogen cyanide $(\mathrm{HCN})$, peroxyacetyl nitrate $\left(\mathrm{CH}_{3} \mathrm{C}(\mathrm{O}) \mathrm{O}_{2} \mathrm{NO}_{2}\right.$, abbreviated as PAN), furan $\left(\mathrm{C}_{4} \mathrm{H}_{4} \mathrm{O}\right)$, acetic acid $\left(\mathrm{CH}_{3} \mathrm{COOH}\right)$ and glycolaldehyde $\left(\mathrm{HOCH}_{2} \mathrm{CHO}\right.$ or hydroxyacetaldehyde). The identification was made with Jacobians obtained from a forward model (with temperature and main absorbers of the US standard atmosphere (NASA-USAF, 1976), where each whitened Jacobian was scaled to match its maximum absolute value with the observed signature in the whitened spectrum. Note that for the figures, the scaling factor was slightly offset, so that the whitened spectra and the whitened Jacobian would not obscure each other.

The observation of $\mathrm{HOCH}_{2} \mathrm{CHO}$ is the first from space to our knowledge. The detection of the Q-branch associated with the $\nu_{10}$ vibrational mode at $860.5 \mathrm{~cm}^{-1}$ (Johnson et al., 2013 ) is promising for future exploitation, as $\mathrm{HOCH}_{2} \mathrm{CHO}$ measurements are very limited at the moment (Treadaway et al., 2018). $\mathrm{HOCH}_{2} \mathrm{CHO}$, as well as all the other detected species, are well-known products of biomass burning (see e.g. Akagi et al. (2011); Andreae (2019) and references therein). In the troposphere it is formed from the oxidation of alkenes, in particular isoprene and several of its degradation products, and it is a key intermediate in the formation pathways of oxygenated compounds such as $\mathrm{HCOOH}$ and glyoxal (Paulot et al., 2009; Taraborrelli et al., 2012). Strong Q-branches of $\mathrm{HCN}, \mathrm{C}_{2} \mathrm{H}_{2}$ and $\mathrm{C}_{4} \mathrm{H}_{4} \mathrm{O}$ are observed between 700 and $800 \mathrm{~cm}^{-1}$, as well as several R lines for $\mathrm{HCN}$ and $\mathrm{C}_{2} \mathrm{H}_{2}$. Note that the strong $\nu_{2}$ band of $\mathrm{CO}_{2}$ present in this spectral region is completely removed by the whitening transformation. For $\mathrm{C}_{2} \mathrm{H}_{2}$, a weaker signal is also detected around 1300-1352 $\mathrm{cm}^{-1} \cdot \mathrm{C}_{2} \mathrm{H}_{4}$ is the species that exhibits the largest signal in the whitened spectrum with a value of -33 at $949.5 \mathrm{~cm}^{-1}$ and several other features on both sides. The detection of the $\nu_{8}$ band of $\mathrm{CH}_{3} \mathrm{OH}$ is also straightforward with the removal of the large ozone band. At longer wavenumbers, $\mathrm{HCOOH}$ is observed in its $\nu_{3}$ band around $1105 \mathrm{~cm}^{-1}$. Finally, we observe the broadband absorbers $\mathrm{PAN}$ and $\mathrm{CH}_{3} \mathrm{COOH}$, which partially overlap between 1150 and $1170 \mathrm{~cm}^{-1}$. PAN also has a remarkable broadband absorption between 780 and $800 \mathrm{~cm}^{-1}$. The remaining part of the spectrum $\left(1400-2760 \mathrm{~cm}^{-1}\right)$ was analyzed carefully, but apart from the large CO absorption features in the region at $2000-2250 \mathrm{~cm}^{-1}$, no other spectral anomalies were identified. However, there are several notable enhancements in the $800-1350 \mathrm{~cm}^{-1}$ range which we were unable to attribute to a specific species. The strongest features are identified by dotted lines in Figure 1, and in particular those that we could also observe in other spectra of the fire plume. Some are very sharp, such as the feature at $840.75 \mathrm{~cm}^{-1}$; others are wider $\left(815-837 \mathrm{~cm}^{-1}\right)$ and these could be due to heavier molecules or a combination of different absorbers. Note that in general, heavier molecules tend to have broader absorption features, for which unambiguous identification can become more difficult, especially when only one feature is identified or when its magnitude is weak.

We also analyzed the whitened spectrum of a fresh fire plume (measured at $39.28^{\circ} \mathrm{S}$, $153.48^{\circ} \mathrm{E}$ on December 30, 2019), as displayed in Figure B1 of Annex B. The fresh plume exhibits very strong signatures of nitrous acid (HONO) and ammonia $\left(\mathrm{NH}_{3}\right)$ that are not seen in the transported plume. This makes sense as these species are known to be emitted 


\section{Long-lived gas analysis over the Pacific Ocean}
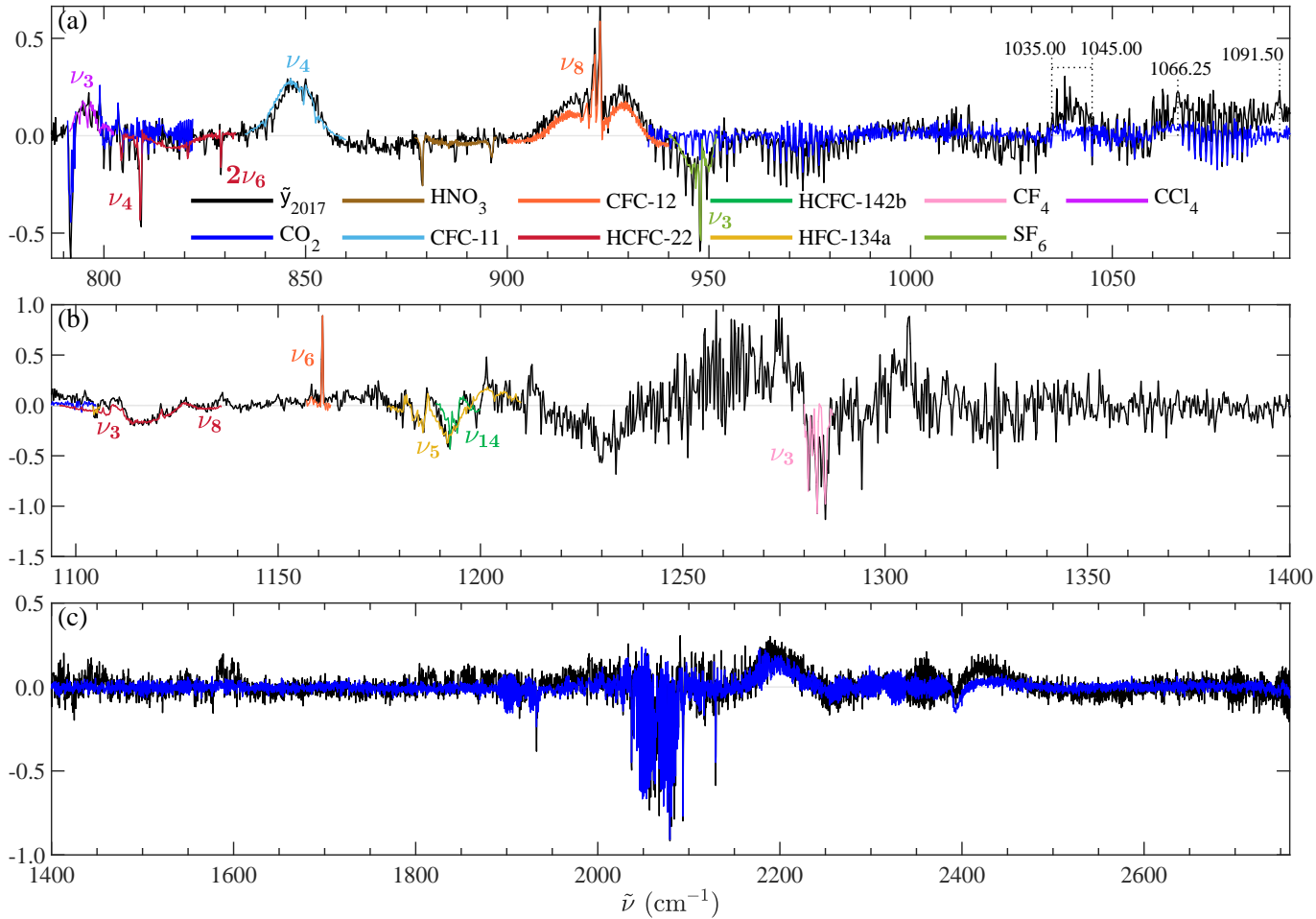

Figure 2. Whitened spectrum of Pacific Ocean from October 2017 revealing eight halocarbons, carbon dioxide and nitric acid.

In this section, we show how small spectral changes that appear over longer time periods in mean spectra can be exposed with the help of the whitening transformation. Focusing over an area in the North Pacific Ocean $\left(25^{\circ}-45^{\circ} \mathrm{N} ; 170^{\circ}-165^{\circ} \mathrm{W}\right)$, we chose 120,000 clear-sky spectra measured in 2008 to calculate a reference mean spectrum and associated covariance matrix. 2008 is the first complete year where IASI L1c reprocessed data are available (Bouillon et al., 2020). The spectrum on which we applied whitening was calculated from $N=20,000$ clear-sky spectra measured in October 2017 over the same area. Using a mean rather than an individual spectrum is not strictly needed, but it helps focusing on longlived compounds, as an individual spectrum might always exhibit anomalies compared to the reference due to natural variations in short-lived trace species. For instance plumes of volatile organic compounds are regularly observed in the North Pacific Ocean (Franco et al., 2018, 2019). The whitened mean spectrum is shown in Figure 2. As we work with mean spectra, the maximum values observed in the whitened spectrum are much lower than in the previous example. However, for the same reason, a significant value is in theory already obtained for values as low as $4 / \sqrt{N} \approx 0.03$. 
Changes in eight halocarbons were identified, these are: CFC-11 $\left(\mathrm{CFCl}_{3}\right), \mathrm{CFC}-12$ $\left(\mathrm{CF}_{2} \mathrm{Cl}_{2}\right)$, HCFC-22 $\left(\mathrm{CHF}_{2} \mathrm{Cl}\right)$, HCFC-142b $\left(\mathrm{CH}_{3} \mathrm{CF}_{2} \mathrm{Cl}\right)$, HFC-134a $\left(\mathrm{CH}_{2} \mathrm{FCF}_{3}\right)$, carbon tetrafluoride $\left(\mathrm{CF}_{4}\right)$, sulfur hexafluoride $\left(\mathrm{SF}_{6}\right)$ and carbon tetrachloride $\left(\mathrm{CCl}_{4}\right)$. Halocarbons are synthetic halogenated compounds used in many industrial and domestic applications (Martinerie et al., 2009). Most of them are powerful greenhouse gases and contribute, for chlorinated and brominated compounds, to the depletion of stratospheric ozone and to the development of ozone hole (World Meteorological Organization, 2010). Of these eight species, five of them (CFC-11, CFC-12, HCFC-22, $\mathrm{CCl}_{4}$ and $\mathrm{CF}_{4}$ ) have been observed in IASI spectra before (Clerbaux et al., 2009; Liuzzi et al., 2016).

The absorption bands of the two CFCs, located around $849 \mathrm{~cm}^{-1}$ for CFC-11 and at $\sim 923$ and $\sim 1161 \mathrm{~cm}^{-1}$ for CFC-12 (here and also later, the wavenumbers refer to the position of strong Q-branches), have whitened signals of $0.3,0.7$ and 0.9 respectively. Those positive values indicate that their atmospheric abundance was smaller in 2017 than in 2008, which is consistent with independent satellite measurements (Chen et al., 2020), independent in-situ measurements (Prinn et al., 2018) and a direct consequence of the 1987 Montreal Protocol to limit the use and production of CFCs (World Meteorological Organization, 2018). The $\nu_{3}$ band of $\mathrm{CCl}_{4}$ shows up at $\sim 796 \mathrm{~cm}^{-1}$ with a whitened signal's value of 0.2 . The production of $\mathrm{CCl}_{4}$ has been controlled by Montreal Protocol as long as CFCs, explaining its decrease between 2008 and 2017.

The other halocarbons in Figure 2 are all detected with a negative value, indicating an increase in their atmospheric concentration between 2008 and 2017. Four absorption bands of HCFC-22 are observed: $\nu_{4}\left(\sim 809.25 \mathrm{~cm}^{-1}\right), 2 \nu_{6}\left(\sim 829.00 \mathrm{~cm}^{-1}\right), \nu_{3}(\sim 1114.00$ $\left.\mathrm{cm}^{-1}\right)$ and $\nu_{8}\left(\sim 1132.25 \mathrm{~cm}^{-1}\right)$. In the spectral region between 1178 and $1200 \mathrm{~cm}^{-1}$, HFC-134a and HCFC-142b are both absorbing. Although the detection of HFC-134a is unambiguous, the detection of HCFC-142b is less certain, but still very likely considering the presence of a sharp feature at $1192.50 \mathrm{~cm}^{-1}$ that would correspond to its $\nu_{14}$ Q-branch. Note that constraints on the production of both HCFCs and HFCs were only added in later amendments of the Montreal Protocol (World Meteorological Organization, 2018). The signatures of $\mathrm{SF}_{6}$ and $\mathrm{CF}_{4}$ are clearly observed at $947.75 \mathrm{~cm}^{-1}$ (Q-branch of the $\nu_{3}$ band with value of -0.6) and around $1283.25 \mathrm{~cm}^{-1}$ (value of -1.1) respectively, and are consistent with increases observed from ground-based measurements (Prinn et al., 2018).

The region $1220-1370 \mathrm{~cm}^{-1}$ is quite complicated for a definite analysis of the individual trends of the atmospheric species contributing to the absorption: $\mathrm{CH}_{4}, \mathrm{~N}_{2} \mathrm{O}, \mathrm{H}_{2} \mathrm{O}, \mathrm{HDO}$, $\mathrm{HNO}_{3}, \mathrm{O}_{3}$. However, in this region the (negative) spectral signatures of $\mathrm{CF}_{4}$ around 1283 $\mathrm{cm}^{-1}$ clearly indicate an increase of its abundance over the considered time frame i.e. 2008 (for the reference) compared to 2017 (for the Pacific data set).

Apart from the halocarbons, Figure 2 highlights several absorption lines of $\mathrm{CO}_{2}$; the signal shows up at $791.5 \mathrm{~cm}^{-1}$ with a succession of rovibrational features around 800, 950, $975,1050,1070$ and $2100 \mathrm{~cm}^{-1}$. The negative values indicate an increase in the $\mathrm{CO}_{2}$ signal, and thus a rise in concentration between 2008 and 2017. The $\mathrm{CO}_{2}$ features in these spectral regions are less saturated than below $750 \mathrm{~cm}^{-1}$, and are less affected by small changes in atmospheric temperatures. There are also absorption features of nitric acid $\left(\mathrm{HNO}_{3}\right)$ in its $\nu_{5}$ and $2 \nu_{9}$ bands: the corresponding signatures are stronger around the two $\mathrm{Q}$ branches centered at 879.00 and $896.00 \mathrm{~cm}^{-1}$ indicating an increasing atmospheric abundance of $\mathrm{HNO}_{3}$. This is consistent with a recent study that reported a small positive trend for $\mathrm{HNO}_{3}$ (Bernath et al., 2020).

A number of smaller features remain unidentified in this spectrum, of which the strongest are spotted by dotted lines in Figure 2. Most of the observed features are found in the atmospheric window between 800 and $1300 \mathrm{~cm}^{-1}$. The broad feature between 1215 and 1240 $\mathrm{cm}^{-1}$ could possibly due to the spectral contribution of $\mathrm{COF}_{2}$. As a caveat, some of these unidentified features could still be due to natural variations of short-lived trace gases. In addition, while the IASI L1c reanalyzed dataset was used for this study, small changes in 
the IASI instrument that occurred in the last decade could also play a role. No major features were identified in the regions impacted by water vapor and $\mathrm{CO}_{2}(645-790,1300-2000$, $\left.2200-2400 \mathrm{~cm}^{-1}\right)$.

\section{Conclusion}

In this letter, we have shown that the whitening transformation allows analyzing anomalies in high resolution infrared spectra. It enables elimination of the large absorption features that usually dominate a spectrum and accentuates those channels which are incompatible with the background norm. We have presented two different applications: an analysis of an extreme event (the 2019/2020 Australian fires) and an analysis of long-term mean changes in IASI spectra. These exploit respectively the spatial variability of reactive species and the temporal variability of long-lived compounds. We have provided spectroscopic evidence of the occurrence of nine fire tracers and eight halocarbons. This includes four species (glycolaldehyde, HCFC-142b, HFC-134a, SF 6 ) which have never been observed before with a nadir sounder. Their detection is very promising, especially for the determination of their source emissions and the study of their temporal evolution.

The advantages of the whitening approach compared to more traditional techniques are numerous. For instance, Clarisse et al. (2011) analyzed spectra from the 2009 Australian fires using a fitting approach, which aims at reconstructing the observed spectrum by means of forward simulations. Especially in extreme cases, it is very difficult and time consuming to obtain reasonable fits of the corresponding spectra, and often fitting windows need to be restricted to narrow spectral ranges. In contrast, whitening is immediate, does not require an inverse model nor the ability of a forward model to account for all the observed features, and can be applied on spectral ranges of any size. Likewise, in a more traditional analysis of trends in high resolution infrared spectra (Brindley et al., 2015; Strow \& DeSouza-Machado, 2020 ), it is very challenging to deal properly with variations of $\mathrm{O}_{3}, \mathrm{CH}_{4}, \mathrm{CO}_{2}$ or $\mathrm{H}_{2} \mathrm{O}$ due to e.g. natural temporal variations, variations in temperature or sampling biases related to clouds; whereas these are dealt with automatically using the whitening technique. 

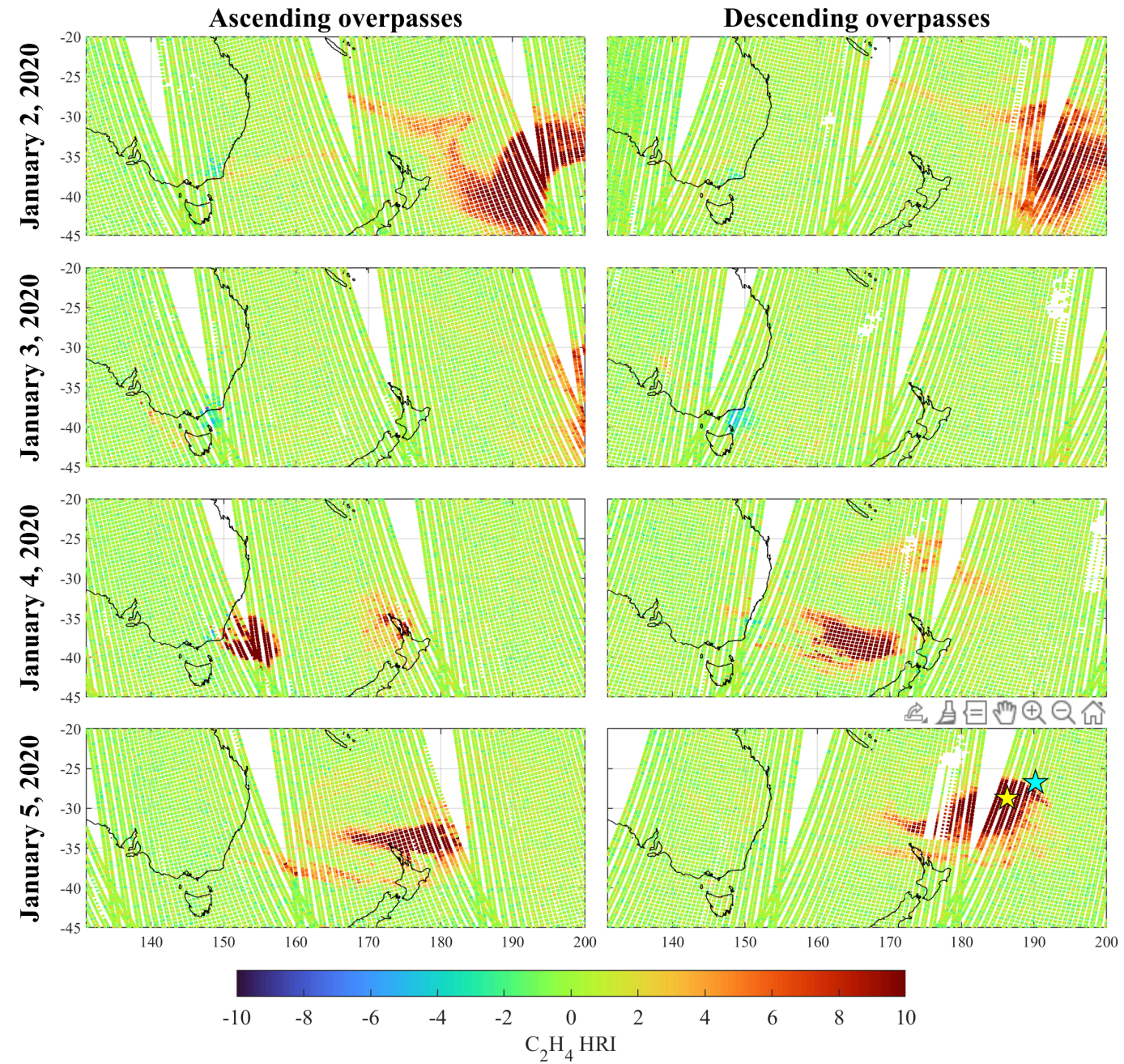

Figure A1. HRI maps of $\mathrm{C}_{2} \mathrm{H}_{4}$ of the 2020 Australian bushfires on selected days. The size of the IASI footprint has been slightly exaggerated for visualization purposes. ( $\downarrow \grave{s}$ and $\boldsymbol{t}$ respectively mark the spectra selected inside and outside the fire plume)

This article is protected by copyright. All rights reserved. 


\section{Appendix B}
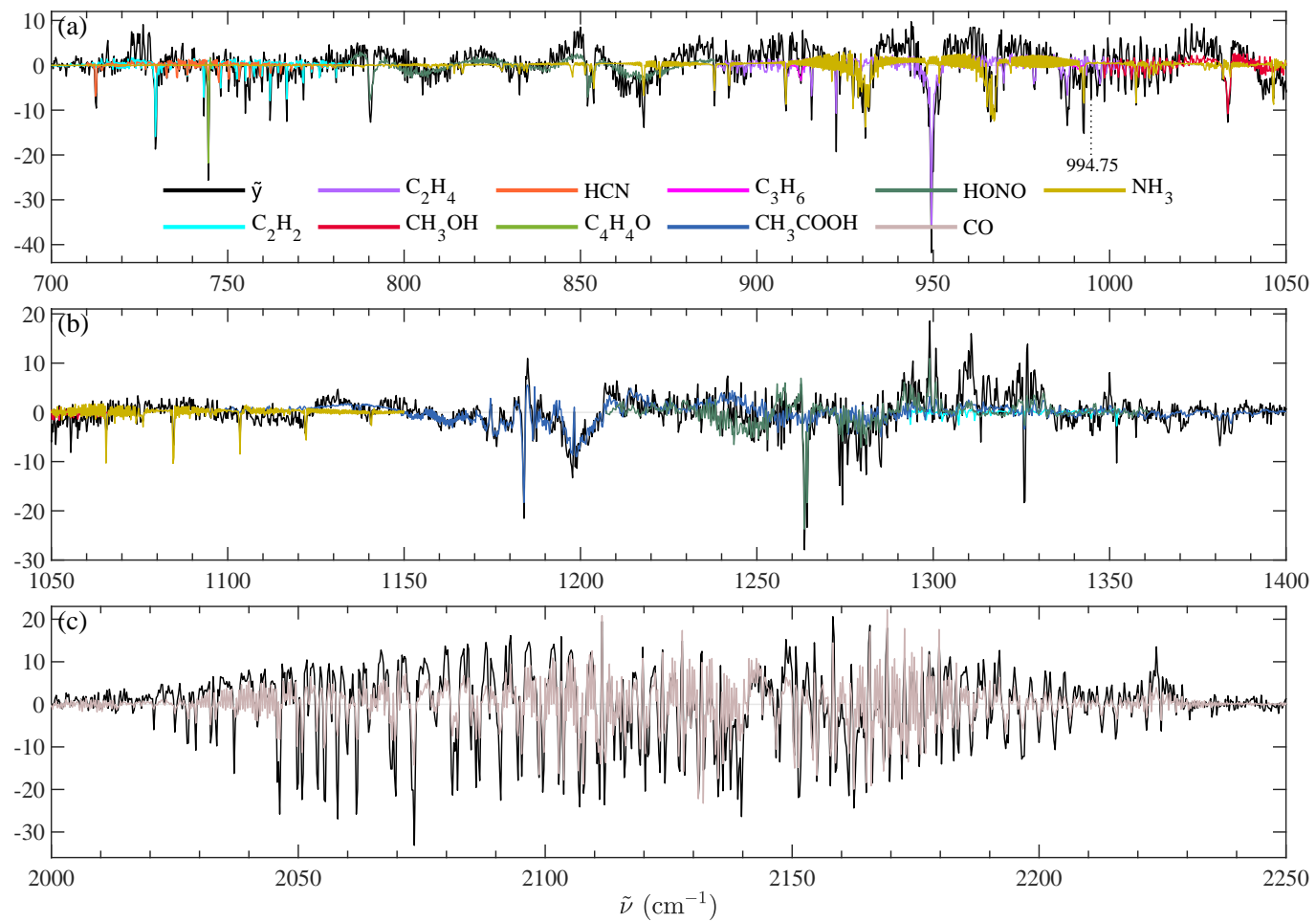

Figure B1. Whitened spectrum of Australian bushfires from December 30, 2019 revealing 8 trace gas species and carbon monoxide.

\section{Acknowledgments}

IASI is a joint mission of EUMETSAT and the Centre National d'Études Spatiales (CNES, France). It is flown aboard the Metop satellites as part of the EUMETSAT Polar System. The IASI L1c data are received through the EUMETCast near-real-time data distribution service. H. De Longueville is grateful for her PhD grant to the "Fonds pour la Formation à la Recherche dans l'Industrie et dans l'Agriculture" of Belgium. L. Clarisse is a research associate supported by the Belgian F.R.S-FNRS. S. Whitburn is grateful to the ERC for funding his research work. S. Bauduin is Chargée de recherches supported by the Belgian F.R.S-FNRS. We thank AERIS and EUMETSAT for providing us the reprocessed L1 IASI record. This project has received funding from the European Research Council (ERC) under the European Union's Horizon 2020 research and innovation program (Grant Agreement 742909). It was also supported by the Prodex arrangement IASI.FLOW (Belspo-ESA). Data were not used, nor created for this research.

\section{References}

Akagi, S. K., Yokelson, R. J., Wiedinmyer, C., Alvarado, M. J., Reid, J. S., Karl, T., ... Wennberg, P. O. (2011). Emission factors for open and domestic biomass burning for use in atmospheric models. Atmospheric Chemistry and Physics, 11(9), 4039-4072. doi: 10.5194/acp-11-4039-2011

Andreae, M. O. (2019). Emission of trace gases and aerosols from biomass burning - an updated assessment. Atmospheric Chemistry and Physics, 19(13), 8523-8546. doi: 
10.5194/acp-19-8523-2019

Beer, R., Shephard, M. W., Kulawik, S. S., Clough, S. A., Eldering, A., Bowman, K. W., ... Worden, J. R. (2008). First satellite observations of lower tropospheric ammonia and methanol. Geophysical Research Letters, 35(9). doi: 10.1029/2008gl033642

Bernath, P., Steffen, J., Crouse, J., \& Boone, C. (2020). Sixteen-year trends in atmospheric trace gases from orbit. Journal of Quantitative Spectroscopy and Radiative Transfer, 253, 107178. doi: 10.1016/j.jqsrt.2020.107178

Boer, M. M., de Dios, V. R., \& Bradstock, R. A. (2020). Unprecedented burn area of Australian mega forest fires. Nature Climate Change, 10(3), 171-172. doi: 10.1038/ s41558-020-0716-1

Bouillon, M., Safieddine, S., Hadji-Lazaro, J., Whitburn, S., Clarisse, L., DoutriauxBoucher, M., ... Clerbaux, C. (2020). Ten-year assessment of IASI radiance and temperature. Remote Sensing, 12(15), 2393. doi: 10.3390/rs12152393

Brindley, H., Bantges, R., Russell, J., Murray, J., Dancel, C., Belotti, C., \& Harries, J. (2015). Spectral signatures of Earth's climate variability over 5 years from IASI. Journal of Climate, 28(4), 1649-1660. doi: 10.1175/jcli-d-14-00431.1

Camy-Peyret, C., Liuzzi, G., Masiello, G., Serio, C., Venafra, S., \& Montzka, S. (2017). Assessment of IASI capability for retrieving carbonyl sulphide (OCS). Journal of Quantitative Spectroscopy and Radiative Transfer, 201, 197-208. doi: 10.1016/j.jqsrt .2017 .07 .006

Chen, X., Huang, X., \& Strow, L. L. (2020). Near-global CFC-11 trends as observed by Atmospheric Infrared Sounder from 2003 to 2018. Journal of Geophysical Research: Atmospheres. doi: 10.1029/2020jd033051

Clarisse, L., Clerbaux, C., Franco, B., Hadji-Lazaro, J., Whitburn, S., Kopp, A. K., ... Coheur, P.-F. (2019). A decadal data set of global atmospheric dust retrieved from IASI satellite measurements. Journal of Geophysical Research: Atmospheres, 124(3), 1618-1647. doi: 10.1029/2018jd029701

Clarisse, L., Coheur, P.-F., Prata, F., Hadji-Lazaro, J., Hurtmans, D., \& Clerbaux, C. (2013). A unified approach to infrared aerosol remote sensing and type specification. Atmospheric Chemistry and Physics, 13(4), 2195-2221. doi: 10.5194/acp-13-2195 $-2013$

Clarisse, L., R'Honi, Y., Coheur, P.-F., Hurtmans, D., \& Clerbaux, C. (2011). Thermal infrared nadir observations of 24 atmospheric gases. Geophysical Research Letters, 38(10). doi: $10.1029 / 2011$ gl047271

Clerbaux, C., Boynard, A., Clarisse, L., George, M., Hadji-Lazaro, J., Herbin, H., ... Coheur, P.-F. (2009). Monitoring of atmospheric composition using the thermal infrared IASI/MetOp sounder. Atmospheric Chemistry and Physics, 9(16), 60416054. doi: 10.5194/acp-9-6041-2009

Coheur, P.-F., Clarisse, L., Turquety, S., Hurtmans, D., \& Clerbaux, C. (2009). IASI measurements of reactive trace species in biomass burning plumes. Atmospheric Chemistry and Physics, 9(15), 5655-5667. doi: 10.5194/acp-9-5655-2009

Coheur, P. F., Clerbaux, C., \& Colin, R. (2003). Spectroscopic measurements of halocarbons and hydrohalocarbons by satellite-borne remote sensors. Journal of Geophysical Research, 108 (D4). doi: 10.1029/2002jd002649

Crevoisier, C., Clerbaux, C., Guidard, V., Phulpin, T., Armante, R., Barret, B., ... Stubenrauch, C. (2014). Towards IASI-new generation (IASI-NG) : impact of improved spectral resolution and radiometric noise on the retrieval of thermodynamic, chemistry and climate variables. Atmospheric Measurement Techniques, 7(12), 4367-4385. doi: 10.5194/amt-7-4367-2014

Franco, B., Clarisse, L., Stavrakou, T., Müller, J.-F., Damme, M. V., Whitburn, S., .. Coheur, P.-F. (2018). A general framework for global retrievals of trace gases from IASI: Application to methanol, formic acid, and PAN. Journal of Geophysical Research: Atmospheres, 123(24). doi: 10.1029/2018jd029633

Franco, B., Clarisse, L., Stavrakou, T., Müller, J.-F., Pozzer, A., Hadji-Lazaro, J., ... Coheur, P.-F. (2019). Acetone atmospheric distribution retrieved from space. Geophysical 
Research Letters, 46(5), 2884-2893. doi: 10.1029/2019g1082052

Grainger, R. G., Peters, D. M., Thomas, G. E., Smith, A. J. A., Siddans, R., Carboni, E., \& Dudhia, A. (2013). Measuring volcanic plume and ash properties from space. Geological Society, London, Special Publications, 380(1), 293-320. doi: 10.1144/sp380 .7

Harries, J. E., Brindley, H. E., Sagoo, P. J., \& Bantges, R. J. (2001). Increases in greenhouse forcing inferred from the outgoing longwave radiation spectra of the Earth in 1970 and 1997. Nature, 410(6826), 355-357. doi: 10.1038/35066553

Hilton, F., Armante, R., August, T., Barnet, C., Bouchard, A., Camy-Peyret, C., ... Zhou, D. (2012). Hyperspectral Earth Observation from IASI: Five Years of Accomplishments. Bulletin of the American Meteorological Society, 93(3), 347-370. doi: 10.1175/bams-d-11-00027.1

Hurley, N., Cheng, Z., \& Zhang, M. (2009). Statistical attack detection. In Proceedings of the third ACM conference on recommender systems - RecSys 09. ACM Press. doi: $10.1145 / 1639714.1639740$

Johnson, T. J., Sams, R. L., Profeta, L. T. M., Akagi, S. K., Burling, I. R., Yokelson, R. J., \& Williams, S. D. (2013). Quantitative IR spectrum and vibrational assignments for glycolaldehyde vapor: Glycolaldehyde measurements in biomass burning plumes. The Journal of Physical Chemistry A, 117(20), 4096-4107. doi: 10.1021/jp311945p

Kessy, A., Lewin, A., \& Strimmer, K. (2018). Optimal Whitening and Decorrelation. The American Statistician, 72(4), 309-314. doi: 10.1080/00031305.2016.1277159

Liuzzi, G., Masiello, G., Serio, C., Venafra, S., \& Camy-Peyret, C. (2016). Physical inversion of the full IASI spectra: Assessment of atmospheric parameters retrievals, consistency of spectroscopy and forward modelling. Journal of Quantitative Spectroscopy and Radiative Transfer, 182, 128-157. doi: 10.1016/j.jqsrt.2016.05.022

Manolakis, D., Lockwood, R., \& Cooley, T. (2016). Hyperspectral imaging remote sensing. Cambridge University Press.

Martinerie, P., Nourtier-Mazauric, E., Barnola, J.-M., Sturges, W. T., Worton, D. R., Atlas, E., ... Brasseur, G. P. (2009). Long-lived halocarbon trends and budgets from atmospheric chemistry modelling constrained with measurements in polar firn. Atmospheric Chemistry and Physics, 9(12), 3911-3934. doi: 10.5194/acp-9-3911-2009

NASA-USAF. (1976). U.S. Standard Atmosphere 1976. Washington, D.C.: U.S. Government Printing Office.

Nolan, R. H., Boer, M. M., Collins, L., de Dios, V. R., Clarke, H., Jenkins, M., . . Bradstock, R. A. (2020). Causes and consequences of Eastern Australias 2019-20 season of megafires. Global Change Biology, 26(3), 1039-1041. doi: 10.1111/gcb.14987

Paulot, F., Crounse, J. D., Kjaergaard, H. G., Kroll, J. H., Seinfeld, J. H., \& Wennberg, P. O. (2009). Isoprene photooxidation: new insights into the production of acids and organic nitrates. Atmospheric Chemistry and Physics, 9(4), 1479-1501. doi: 10.5194/acp-9-1479-2009

Prinn, R. G., Weiss, R. F., Arduini, J., Arnold, T., DeWitt, H. L., Fraser, P. J., ... Zhou, L. (2018). History of chemically and radiatively important atmospheric gases from the Advanced Global Atmospheric Gases Experiment (AGAGE). Earth System Science Data, 10(2), 985-1018. doi: 10.5194/essd-10-985-2018

Reed, I., Mallett, J., \& Brennan, L. (1974). Rapid convergence rate in adaptive arrays. IEEE Transactions on Aerospace and Electronic Systems, AES-10(6), 853-863. doi: 10.1109 /taes.1974.307893

Rodgers, C. D. (2000). Inverse methods for atmospheric sounding. World Scientific. doi: $10.1142 / 3171$

Scharf, L. (1991). Statistical signal processing. Pearson Education (US).

Stavrakou, T., Müller, J.-F., Peeters, J., Razavi, A., Clarisse, L., Clerbaux, C., .. PatonWalsh, C. (2011). Satellite evidence for a large source of formic acid from boreal and tropical forests. Nature Geoscience, 5(1), 26-30. doi: 10.1038/ngeo1354

Strow, L. L., \& DeSouza-Machado, S. (2020). Establishment of AIRS climate-level radiometric stability using radiance anomaly retrievals of minor gases and SST. 
doi: $10.5194 /$ amt-2019-504

Taraborrelli, D., Lawrence, M. G., Crowley, J. N., Dillon, T. J., Gromov, S., Groß, C. B. M., ... Lelieveld, J. (2012). Hydroxyl radical buffered by isoprene oxidation over tropical forests. Nature Geoscience, 5(3), 190-193. doi: 10.1038/ngeo1405

Taylor, I. A., Preston, J., Carboni, E., Mather, T. A., Grainger, R. G., Theys, N., ... Kilbride, B. M. (2018). Exploring the utility of IASI for monitoring volcanic $\mathrm{SO}_{2}$ emissions. Journal of Geophysical Research: Atmospheres, 123(10), 5588-5606. doi: 10.1002/2017jd027109

Theys, N., Volkamer, R., Müller, J.-F., Zarzana, K. J., Kille, N., Clarisse, L., ... Van Roozendael, M. (2020). Global nitrous acid emissions and levels of regional oxidants enhanced by wildfires. Nature Geoscience, 13(10), 681-686. doi: 10.1038/s41561-020 -0637-7

Treadaway, V., Heikes, B. G., McNeill, A. S., Silwal, I. K. C., \& O'Sullivan, D. W. (2018). Measurement of formic acid, acetic acid and hydroxyacetaldehyde, hydrogen peroxide, and methyl peroxide in air by chemical ionization mass spectrometry: airborne method development. Atmospheric Measurement Techniques, 11 (4), 1901-1920. doi: 10.5194/ amt-11-1901-2018

Van Damme, M., Clarisse, L., Heald, C. L., Hurtmans, D., Ngadi, Y., Clerbaux, C., ... Coheur, P. F. (2014). Global distributions, time series and error characterization of atmospheric ammonia $\left(\mathrm{NH}_{3}\right)$ from IASI satellite observations. Atmospheric Chemistry and Physics, 14 (6), 2905-2922. doi: 10.5194/acp-14-2905-2014

Van Damme, M., Clarisse, L., Whitburn, S., Hadji-Lazaro, J., Hurtmans, D., Clerbaux, C., \& Coheur, P.-F. (2018). Industrial and agricultural ammonia point sources exposed. Nature, 564(7734), 99-103. doi: 10.1038/s41586-018-0747-1

Walker, J. C., Dudhia, A., \& Carboni, E. (2011). An effective method for the detection of trace species demonstrated using the MetOp Infrared Atmospheric Sounding Interferometer. Atmospheric Measurement Techniques, 4(8), 1567-1580. doi: 10.5194/amt-4-1567-2011

Whitburn, S., Van Damme, M., Clarisse, L., Hurtmans, D., Clerbaux, C., \& Coheur, P.-F. (2017). IASI-derived $\mathrm{NH}_{3}$ enhancement ratios relative to $\mathrm{CO}$ for the tropical biomass burning regions. Atmospheric Chemistry and Physics, 17(19), 12239-12252. doi: 10.5194/acp-17-12239-2017

Winker, D. M., Vaughan, M. A., Omar, A., Hu, Y., Powell, K. A., Liu, Z., ... Young, S. A. (2009). Overview of the CALIPSO mission and CALIOP data processing algorithms. Journal of Atmospheric and Oceanic Technology, 26(11), 2310-2323. doi: $10.1175 / 2009$ jtecha1281.1

World Meteorological Organization. (2010). Scientific Assessment of Ozone Depletion : 2010 (Tech. Rep. No. 52). Geneva, Switzerland: Global Ozone Research and Monitoring Project.

World Meteorological Organization. (2018). Scientific Assessment of Ozone Depletion: 2018 (Tech. Rep. No. 58). Geneva, Switzerland: Global Ozone Research and Monitoring Project. 